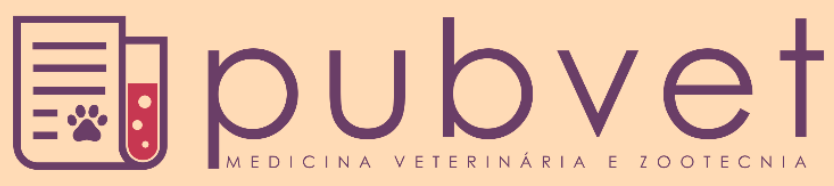

https://doi.org/10.31533/pubvet.v15n09a903.1-12

\title{
Análise de boas práticas de fabricação em usinas de beneficiamento de leite caprino no Cariri
}

\author{
Filipe Jordão Pereira de Medeiros ${ }^{1 *} \bullet$, Joyce Galvão de $\operatorname{Souza}^{2} \bullet \mathbb{D}$, Iara Nunes de Siqueira ${ }^{2} \bullet$, \\ Francisco Rodrigues de Araújo Junior ${ }^{1} \bullet$, José Givanildo da Silva ${ }^{3} \bullet$
}

${ }^{1}$ Acadêmico de Medicina Veterinária pela Universidade Federal de Campina Grande, Unidade Acadêmica de Medicina Veterinária, Patos, PB Brasil. ${ }^{2}$ Pós-graduanda pela Universidade Federal de Campina Grande, Programa de Pós-Graduação em Ciência e Saúde Animal, Patos, PB Brasil. ${ }^{3}$ Professor substituto de Medicina Veterinária pela Universidade Federal de Campina Grande, Unidade Acadêmica de Medicina Veterinária, Patos, PB Brasil. *Autor para correspondência, E-mail: filipejordaomedvet@gmail.com,fco.juniorr@gmail.com

Resumo. A procura crescente por alimentos seguros tem resultado em uma necessidade das indústrias se adequarem às normas estabelecidas para garantir produtos de qualidade que não ofereçam riscos à saúde dos consumidores. Diversos são os fatores que podem influenciar na qualidade do leite e podem torná-lo um produto impróprio para o consumo humano, como fatores físicos, químicos ou biológicos, os quais poderão contaminar o leite em decorrência de falhas na sua obtenção, no seu processamento ou expedição. Dessa forma, é essencial que estabelecimentos produtores/industrializadores de alimentos obtenham excelentes percentuais de conformidades no que diz respeito às Boas Práticas de Fabricação (BPF), as quais são medidas que devem ser implementadas por indústrias alimentícias com o intuito de garantir os requisitos necessários para a produção de alimentos seguros. O presente trabalho teve como objetivo avaliar a aplicação das BPF, em usinas de beneficiamento de leite caprino, na região do Cariri paraibano. Foram visitadas quatro usinas de beneficiamento, denominadas de A, B, $\mathrm{C}$ e D, sendo verificadas se estão de acordo com as normas de BPF's. A partir da análise observacional realizada, foi constatado que, dos quatro estabelecimentos estudados apenas as usinas de beneficiamento A e $\mathrm{C}$ foram classificadas em grupo 1, sendo considerada de baixo risco à segurança alimentar, e as usinas $\mathrm{B}$ e $\mathrm{D}$, por sua vez, foram enquadradas no grupo 2 , as quais ofereciam médio risco à segurança alimentar. Foram observadas não conformidades em todos os cinco quesitos da lista, em todos os estabelecimentos, sendo descritas falhas nas edificações, falta de produtos relacionados a higiene pessoal, presença de pragas no interior da indústria, e principalmente, o não cumprimento de alguns Procedimentos de Operações Padronizados. O presente estudo demonstrou que as usinas B e D deverão melhorar seus níveis em relação as BPF's, tanto para atender os requisitos da legislação vigente, como para oferecer produtos mais seguros aos seus consumidores, tendo em vista o grande número de não conformidades observadas nesses estabelecimentos. Também se faz necessária uma fiscalização mais efetiva dos órgãos competentes para garantir que os estabelecimentos se adequem a todos os quesitos das BPF's, evitando assim o risco da veiculação de doenças alimentares aos consumidores, desperdícios de matéria-prima bem como prejuízos financeiros para o estabelecimento.

Palavras-chave: Alimento, indústria, produção, qualidade, segurança

\section{Analysis of good manufacturing practices in goat milk processing plants in Cariri}

Abstract. The growing demand for safe food has resulted in a need for industries to adapt to established standards to ensure quality products that do not pose risks to consumers' health. There are several factors that can influence the quality of the milk and can make it an inappropriate 
product for human consumption, such as physical, chemical or biological factors that may contaminate the milk due to failures in obtaining, processing or shipping it. Thus, it is essential that food producing / industrializing establishments obtain excellent percentages of conformities about GMP's, which are measures that must be implemented by food industries in order to guarantee the necessary requirements for food production safe. The present work aimed to evaluate the application of Good Manufacturing Practices (GMP), in caprine milk processing units, in the Cariri region of Paraíba. Four processing units were visited, called A, B, C and D, and were checked for compliance with GMP standards. From the observational analysis carried out, it was found that, of the four establishments studied, only processing plants $\mathrm{A}$ and $\mathrm{C}$ were classified in group 1 , being considered of low risk to food security, plants B and D, in turn, were classified in group 2, which offered a medium risk to food security. Non-conformities were observed in all five items on the list, in all establishments, being described flaws in buildings, lack of products related to personal hygiene, presence of pests within the industry, and mainly, noncompliance with some Operations Procedures Standardized. The present study demonstrated that plants B and D should improve their levels in relation to GMP's, both to meet the requirements of current legislation and to offer safer products to their consumers, in view of the large number of non-conformities observed in these establishments. It is also necessary to have a more effective inspection of the competent bodies to ensure that the establishments are adapted to all GMP's requirements, thus avoiding the risk of transmitting foodborne illnesses to consumers, waste of raw materials as well as financial losses for the establishment.

Keywords: Food, industry, production, quality, safety

\section{Análisis de buenas prácticas de fabricación en plantas procesadoras de leche de cabra en Cariri}

Resumen. La creciente demanda de alimentos seguros ha resultado en la necesidad de que las industrias cumplan con los estándares establecidos para garantizar productos de calidad que no presenten riesgos para la salud de los consumidores. Existen varios factores que pueden influir en la calidad de la leche y pueden convertirla en un producto inadecuado para el consumo humano, como son los factores físicos, químicos o biológicos que pueden contaminar la leche por fallas en su obtención, procesamiento o envío. Por ello, es fundamental que los establecimientos productores / industrializadores de alimentos obtengan excelentes porcentajes de conformidad con respecto a las Buenas Prácticas de Manufactura (BPF), las cuales son medidas que deben ser implementadas por las industrias alimentarias a fin de garantizar los requisitos necesarios para la producción de alimentos seguros. El presente trabajo tiene como objetivo evaluar la aplicación de BPF en plantas procesadoras de leche de cabra, en la región Cariri de Paraíba. Se visitaron cuatro plantas de beneficio, denominadas A, B, C y D, verificándose si cumplen con las normas GMP. A partir del análisis observacional realizado, se encontró que, de los cuatro establecimientos estudiados, solo las plantas procesadoras A y C fueron clasificadas en el grupo 1, considerándose de bajo riesgo para la seguridad alimentaria, las plantas B y D, a su vez, se enmarcaron en grupo 2, que ofrecía un riesgo medio para la seguridad alimentaria. Se observaron no conformidades en los cinco ítems de la lista, en todos los establecimientos, describiéndose fallas en las edificaciones, falta de productos relacionados con la higiene personal, presencia de plagas dentro de la industria, y principalmente, incumplimiento de algunos Procedimientos Operativos Estandarizados. El presente estudio demuestra que las plantas B y D deben mejorar sus niveles en relación con las BPM, tanto para cumplir con los requisitos de la legislación vigente, como para ofrecer productos más seguros a sus consumidores, dada la gran cantidad de no conformidades observadas en estos establecimientos. También es necesario tener una inspección más efectiva de los organismos competentes para asegurar que los establecimientos se adapten a todos los requisitos de las BPM, evitando así el riesgo de contagio de enfermedades de origen alimentario a los consumidores, desperdicio de materias primas, así como pérdidas económicas para el establecimiento.

Palabras clave: Alimentos, industria, producción, calidad, seguridad 


\section{Introdução}

Segundo dados do Instituto Brasileiro de Geografia e Estatística (IBGE), foram produzidos aproximadamente 25.353.000 litros de leite caprino no Brasil, e desse total produzido, 5.627.000 litros correspondem ao estado da Paraíba (IBGE, 2017). Boa parte da produção do estado corresponde a região do cariri, onde a caprinocultura leiteira desempenha um excelente papel socioeconômico (Bandeira et al., 2007).

O leite é mencionado como um alimento de alto valor biológico, e isso de certo modo o torna um excelente meio para proliferação de microrganismos oportunistas, sendo sua qualidade influenciada por agentes microbiológicos, físicos e químicos. Com isso, é de suma importância que as indústrias de laticínios tomem os cuidados necessários para que seja certificada a qualidade do produto que será comercializado (Novo \& Schiffler, 2006).

As BPFs, são um conjunto de medidas que devem ser adotadas por indústrias de alimentos tendo como principal objetivo a garantia da qualidade sanitária e a manutenção da conformidade dos alimentos de acordo com os seus regulamentos técnicos, sendo essencial para a implementação de qualquer programa de qualidade alimentícia (ANVISA, 2002). Com isso, para a garantia dos produtos produzidos, as BPFs dão informações de como devem ser as instalações da indústria, o comportamento dos trabalhadores e manipuladores de alimentos, as operações de recepção da matéria-prima, seu processamento e expedição, além disso, também realçam a importância do controle de pragas e dos registros e documentação (Ferreira et al., 2004; Magalhães et al., 2006; Santos \& Hoffmann, 2010).

Desta forma, objetivou-se com este estudo, analisar a aplicação das Boas Práticas de Fabricação em usinas de beneficiamento de leite de cabra no Cariri paraibano, descrevendo as principais conformidades e não conformidades observadas e identificando os possíveis riscos à segurança alimentar que essas não conformidades podem ocasionar.

\section{Material e métodos}

O estudo foi realizado em quatro usinas de beneficiamento de leite caprino, localizadas em quatro cidades da região do Cariri paraibano. As usinas eram cadastradas no Serviço de Inspeção Estadual (SIE) e recebiam de 800 a 3.200 litros de leite caprino diariamente.

A coleta de dados foi realizada no mês de janeiro de 2020, sendo obtida por meio de observação direta e aplicação da lista de verificação presente no Anexo II da Resolução de Diretoria Colegiada RDC n ${ }^{\circ} 275$ de 21 de outubro de 2002, imposta pela Agência Nacional de Vigilância Sanitária (ANVISA), juntamente com o Ministério da Saúde (MS). Para o preenchimento da lista foi acompanhada toda a linha produtiva das usinas, desde a recepção do leite, processamento e expedição.

A lista em questão é composta por 164 itens, subdivididos em cinco quesitos, sendo eles: edificações e instalações (79 itens); equipamentos, móveis e utensílios (21 itens); manipuladores (14 itens); produção e transporte do alimento (33 itens); e por último o quesito relacionado à documentação (17 itens). A check-list é composta por três respostas, sendo elas: SIM (item em conformidade), NÃO (item em não conformidade) e NA (quando o quesito não se aplicava ao estabelecimento) pelo fato de não ser necessário, como nos casos de elevadores ou escadas, os quais não são necessários se a indústria for de construção, térrea por exemplo.

Quando o quesito avaliado estava conforme com a legislação, marcava-se na lista "SIM", quando não estava conforme, marcava-se "NÃO", já o item "NA" só era marcado quando o quesito não estava presente na indústria.

A análise dos resultados seguiu metodologia utilizada por Oliveira et al. (2018), onde as quatro indústrias foram codificas em A, B, C e D, e para cada resposta "SIM" foi atribuído um ponto, para as respostas "NÃO", foi atribuído zero pontos, sendo desconsiderados os itens "NA" para não influenciar no resultado final.

Foi realizado o cálculo percentual de conformidade geral de cada usina (A, B, C e D) assim como o percentual de cada um dos cinco quesitos da lista (edificações e instalações; equipamentos, móveis e utensílios; manipuladores; produção e transporte do alimento; e documentação, referente a cada usina pesquisada), com o intuito de se obter um resultado mais detalhado a respeito de qual quesito de cada 
indústria referente às BPFs estava sendo mais acometido com padrões de não conformidade. Os cálculos percentuais de conformidades geral (usina A, B, C e D), e de cada quesito (edificações e instalações; equipamentos, móveis e utensílios; manipuladores; produção e transporte do alimento; documentação) referente a cada usina foram realizados utilizando a seguinte fórmula:

$\%$ de conformidades $=$ Total de conformidades $\times 100$

Total de itens - itens NA

O cálculo da média geral das usinas do Cariri paraibano, levando em consideração os quesitos de edificações e instalações; equipamentos, móveis e utensílios; manipuladores; produção e transporte do alimento; e documentação foi realizado utilizando a seguinte fórmula:

$\%$ Média geral cada quesito $=(\%$ cada quesito usina $\mathrm{A}+\mathrm{B}+\mathrm{C}+\mathrm{D})$

4

As indústrias foram classificadas em: grupo 1 (os que atendiam de $76 \%$ a $100 \%$ de conformidades), grupo 2 (os que atendiam de $51 \%$ a $75 \%$ de conformidades) e grupo 3 (os que atendiam de $0 \%$ a $50 \%$ de conformidades) (ANVISA, 2002), sendo o grupo 1 considerado de baixo risco, o grupo 2 considerado de médio risco e o grupo 3 de alto risco à segurança alimentar (Oliveira et al., 2018).

\section{Resultados e discussão}

$\mathrm{O}$ leite recepcionado em todas as usinas era proveniente de pequenos produtores, sendo considerado uma das principais fontes de renda da região. Dos quatro estabelecimentos participantes da pesquisa, apenas a usina B realizava tanto a pasteurização do leite como produção de derivados lácteos (queijo). Os demais, A, C e D, realizavam apenas a pasteurização do leite e sua expedição.

Conforme pode ser observado na Tabela 1 , dos quatro estabelecimentos analisados quanto às adequações das BPFs, dois (usinas B e D) apresentaram porcentagem acima de $51 \%$ e abaixo de $75 \%$, o que as enquadra em grupo 2, apresentando médio risco à segurança alimentar. Poerner et al. (2009) e Oliveira et al. (2018), em estudos que verificaram as condições higiênico sanitárias em serviços de alimentação e condições higiênico sanitárias do processo de fabricação do queijo de coalho, respectivamente, também observaram estabelecimentos com percentual nesse mesmo intervalo, enquadrando-os em grupo 2, sendo classificados como de risco médio à segurança alimentar.

Tabela 1. Classificação das usinas de beneficiamento de acordo com o percentual de conformidades quanto ao nível de Boas Práticas de Fabricação (BPFs).

\begin{tabular}{lcc}
\hline Usina & Conformidades (\%) & Classificação \\
\hline A & 87,58 & Baixo risco \\
B & 63,64 & Médio risco \\
C & 87,10 & Baixo risco \\
D & 72,10 & Médio risco \\
\hline
\end{tabular}

Os estabelecimentos A e C, apresentaram porcentagens acima de $76 \%$ de conformidade (tabela 1), sendo classificados em grupo 1 . Os resultados desses dois estabelecimentos se assemelham bastante aos encontrados por Figueiredo et al. (2016), que também observaram percentuais de conformidades acima de $76 \%$ em seu estudo, sendo o estabelecimento também enquadrado em grupo 1, apresentando baixo risco à segurança alimentar.

Nenhum dos estabelecimentos do presente estudo foi enquadrado em grupo 3 (alto risco), diferentemente dos resultados encontrados por Oliveira et al. (2018), que em trabalho realizado em oito queijarias, seis apresentaram porcentagem de conformidade inferior a $51 \%$, encontrando até estabelecimentos com apenas 5\% de conformidades, sendo esses classificados como de alto risco para veiculação de Doenças Transmissíveis por Alimentos (DTAs) e sem nenhuma segurança para garantir a qualidade do produto.

Observou-se que, para que os estabelecimentos B e D atinjam $76 \%$ de conformidade e sejam classificados em grupo 1, de baixo risco, devem aumentar seus percentuais em 12,36\% e 3,9\%, respectivamente, o que de fato não são percentuais tão elevados, como os encontrados por Oliveira et al. (2018), onde alguns estabelecimentos teriam que aumentar seus percentuais em até $70 \%$ para serem classificados em grupo 1. 
Com relação às edificações e instalações, onde seus resultados percentuais estão descritos no gráfico $\underline{1}$, todas usinas de beneficiamento apresentaram conformidade para o tópico referente ao acesso à indústria, pelo fato de ser direto e não comum a outro uso. Os estabelecimentos também apresentaram conformidade para o teto, paredes e divisórias, que apresentaram acabamento liso, de cor clara e de fácil limpeza. As portas também estavam em conformidade, sendo de material de fácil higienização e sem falhas de revestimento. Okura \& Moacir (2010) também observaram tais conformidades em seu estudo, relatando que elas dificultam a contaminação cruzada do alimento, pois evitam acúmulo de poeira e facilitam a limpeza e desinfecção das mesmas.

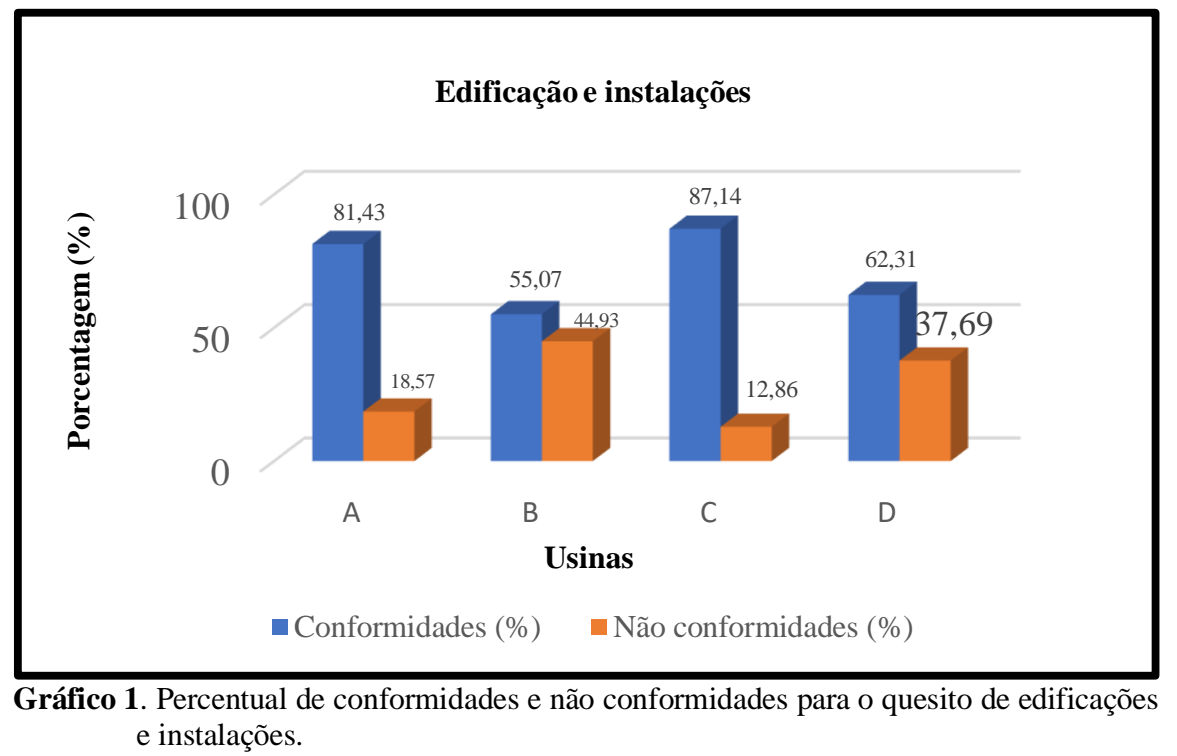

Em contrapartida, apesar de todos estabelecimentos apresentarem-se conformes para os itens mencionados no parágrafo anterior, foram observadas irregularidades com relação a ausência de ângulos abaulados entre as paredes e o teto em todos estabelecimentos (usinas A, B, C e D). Figueiredo et al. (2016), em trabalho cujo objetivo foi realizar a verificação das condições higiênico sanitárias de um laticínio no Pará, também relataram a mesma não conformidade. A Portaria no 326/97 da Secretaria de Vigilância Sanitária, afirma que os ângulos abaulados entre piso e parede e entre parede e teto são incrementados para facilitar a higienização do local, para que com isso não se acumule resíduos e consequentemente não haja proliferação de microrganismos.

Nas usinas B e D (50\%) foi observada presença de lixo, bem como materiais amontoados e quebrados sem nenhuma utilidade (Figuras 1A, 1B e 1C). Segundo a Empresa de Assistência Técnica e Extensão Rural (EMATER) (2009), manter materiais amontoados na área interna ou externa da indústria, favorece o aparecimento de pragas no estabelecimento. Silva et al. (2010), cujo trabalho avaliou as principais não conformidades em laticínios, também observaram que 50\% dos estabelecimentos estudados apresentavam fatores propícios à atração e abrigo de pragas na indústria, sendo esse resultado similar ao encontrado no presente estudo.

Para os itens referentes ao leiaute, todos os estabelecimentos apresentaram-se conformes, pois o número, capacidade e distribuição das dependências estavam de acordo com a atividade desenvolvida. $\mathrm{O}$ volume de produção e expedição que os estabelecimentos suportavam também se encontravam em conformidade, sendo respeitados em todos os estabelecimentos. As áreas para recepção, depósito de matéria-prima, ingredientes e embalagens, eram distintas das áreas de produção, armazenamento e expedição do produto final, o que de fato é bastante benéfico para o fluxograma produtivo das usinas. Segundo Góes \& Silva (2011), os leiautes facilitam o fluxo de materiais e pessoas no estabelecimento, melhoram o espaço disponível no mesmo e permitem um maior controle da quantidade e qualidade da produção e operações, além do que, tais medidas dificultam a contaminação cruzada, sendo esses padrões de não conformidades bastante descritos, como no trabalho de Santos \& Hoffmann (2010), que encontraram $100 \%$ de não conformidades para esse tópico.

Foi constatado também nos estabelecimentos $\mathrm{C}$ e $\mathrm{D}$, pisos em condições inadequadas com presença de rachaduras e pequenos buracos. Oliveira et al. (2018), ao avaliarem oito queijarias, relataram a mesma 
não conformidade, afirmando que esse problema também pode gerar dificuldades de limpeza e acúmulo de resíduos, favorecendo assim a colonização de microrganismos no ambiente.



Figura 1. Não conformidades verificadas nos estabelecimentos produtores de leite caprino da região do cariri paraibano. A. Materiais amontoados, em desuso; B. Acúmulo de lixo no interior da usina; C. Pneus e restos de materiais de construção em desuso.

No estabelecimento $C$, havia a presença de janelas quebradas, ou seja, em condições inadequadas de uso, além de telas de proteção rasgadas, o que permitia a entrada de moscas e outros insetos para o interior da indústria (Figura 2A e 2B). Segundo a Secretaria de Vigilância Sanitária do Ministério da Saúde (SVS/MS) (1997), todas janelas e demais aberturas que se comuniquem com a área externa da indústria deverão possuir proteções contra pragas em bom estado de conservação.

Na usina B, além de algumas irregularidades citadas acima, como janelas quebradas e telas de proteção rasgadas, foi observada a presença de moscas e borboletas na sala de processamento de queijos (Figura 2C). Esse fator pode ser em decorrência das falhas nas janelas, atreladas com as irregularidades nas telas de proteção da indústria ou até mesmo em falhas na execução do controle de pragas. Cardozo (2007) relatou que esses insetos, quando presentes em ambientes de processamento de leite ou de produtos lácteos como o queijo, podem facilmente contaminar o alimento produzido, funcionando como um vetor mecânico de Salmonella spp., Staphylococcus aureus e Escherichia coli, bactérias que podem causar doenças caso algum indivíduo consuma o alimento contaminado.

As iluminações e instalações elétricas também estavam adequadas às atividades desenvolvidas, sem ofuscamentos, apresentando-se embutidas, isoladas e com proteções na maioria dos estabelecimentos. A única usina que apresentou não conformidade para esse tópico foi a $\mathrm{B}$, na qual a instalação elétrica, apresentava fios expostos na área de processamento da indústria (Figura 3C) o que, de certa forma, poderia favorecer à curtos-circuitos e/ou acidentes elétricos com os colaboradores desse estabelecimento. O que de fato não está de acordo com o tópico 1.13.3 da RDC nº 275 de 21 de outubro de 2002 da ANVISA, o qual relata que as instalações elétricas devem estar embutidas ou protegidas em tubulações isolantes, tanto para facilitar a limpeza, como para garantir a segurança do estabelecimento.

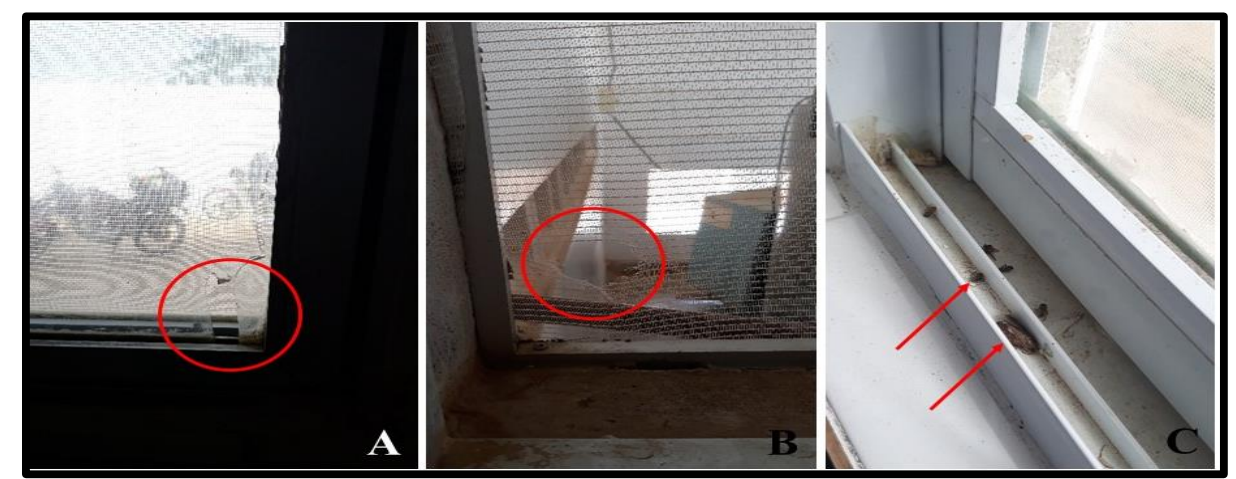

Figura 2. Não conformidades verificadas nos estabelecimentos produtores de leite caprino da região do Cariri paraibano. A. Janela quebrada (Destacada pelo círculo vermelho); B. Tela rasgada que permitia entrada de pragas (Destacada pelo círculo vermelho; C. Pragas em sala de processamento de queijos (Setas vermelhas). 
Outros fatores observados em algumas usinas foram as vias de acesso sem pavimentação, com focos de poeira e terra, onde, segundo Santos \& Hoffmann (2010), a falta de pavimentação favorece a entrada de poeira no interior da indústria, facilitado pelas correntes de ar. Na presente pesquisa, em algumas usinas havia a presença de pedilúvio, entretanto, sem água para sua utilização. É sabido que tal fator pode agir também como facilitador para a entrada de poeira dentro das instalações, mantendo o ambiente de processamento sujo e consequentemente contaminando as matérias primas e/ou produtos.

Com relação às instalações sanitárias e vestiários para os manipuladores, todos estabelecimentos possuíam banheiros em boas condições de infraestrutura, com pisos, paredes, iluminação e ventilação adequadas. Esses por sua vez também eram independentes para cada sexo, sendo localizados em locais isolados da área de produção da indústria, o que diminuí as chances de contaminação cruzada do alimento por não haver comunicação direta, contudo, apesar das conformidades relatadas, foi observado a falta de produtos para higienização das mãos, e a falta de cartilhas informando a importância e correta higienização das mesmas, tanto nos banheiros como na sala de processamento dos estabelecimentos B e D. A falta de produtos e avisos para a correta higienização das mãos dos manipuladores, poderá favorecer a contaminação dos alimentos, pois, segundo Rubin et al. (2012), uma das principais fontes de contaminação decorre de condutas errôneas de higienização das mãos.

As usinas $\mathrm{B}$ e $\mathrm{D}$ não possuíam registros referentes à frequência de higienização da indústria e do reservatório de água. O reservatório de água do estabelecimento $\mathrm{B}$, não estava vedado corretamente (Figura 3A) o que podia favorecer a entrada de sujidades e pragas, contaminando a água a ser utilizada em todo estabelecimento. Segundo Germano \& Germano (2008), a vedação inadequada é uma das causas mais frequentes de contaminação da água nos reservatórios além da inexistência de um programa de limpeza realizado de forma regular e periódica.

O encanamento do estabelecimento B também estava em condições insatisfatórias, com presença de ferrugem, além de solução improvisada para o suporte dos mesmos, conforme figura 2B. Siqueira et al. (2010) relataram que a água pode ser contaminada tanto no seu local de origem como também em sua distribuição. Esse dado reitera a necessidade de que as indústrias tenham sistemas de encanamento adequado e em perfeitas condições de uso.

Para o quesito de equipamentos, móveis e utensílios (Gráfico 2), todos os estabelecimentos apresentaram equipamentos da linha de produção com desenho e número adequados, sendo de superfície lisa, impermeáveis e resistentes à corrosão, o que permitia higienização adequada. Segundo Silva et al. (2010), é essencial que os equipamentos e utensílios sejam de materiais que não transmitam substâncias tóxicas à matéria-prima, que sejam não absorventes e capazes de resistirem a várias operações de limpeza e desinfecção. Okura \& Moacir (2010), assim como no presente estudo também descreveu um alto percentual de conformidade nesse quesito, onde, de seis estabelecimentos pesquisados, apenas um apresentou não conformidade, o que de certa forma, é um ponto bastante positivo, visto que, os equipamentos estão em contato direto com o alimento em processamento.

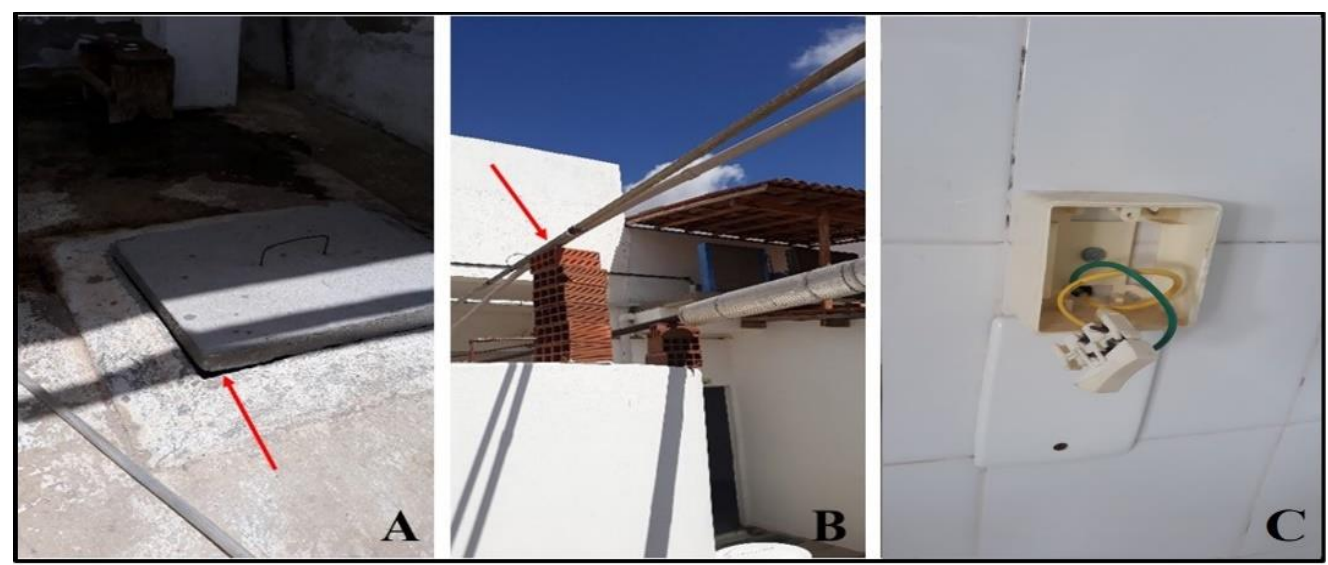

Figura 3. Não conformidades verificadas nos estabelecimentos produtores de leite caprino da região do cariri paraibano. A. Reservatório de água com vedação inadequada (Seta vermelha); B. Solução improvisada (gambiarra) (Seta vermelha); C. Fios elétricos sem isolamento na área de processamento. 
Entretanto, apesar das conformidades relatadas no parágrafo anterior, todas as usinas apresentaram inadequações com relação aos registros que comprovam a calibração e manutenção dos equipamentos. Quintão et al. (2013), em trabalho realizado para avaliar as Boas Práticas de Fabricação em um laticínio na cidade de Rio Pomba/MG, também observaram a mesma não conformidade, Silva et al. (2010) em estudo realizado em 10 laticínios, constataram que $90 \%$ dos estabelecimentos apresentaram não conformidade para esse item, ressaltando que esse padrão de não conformidade apresenta um nível de severidade médio à segurança do alimento, pois equipamentos descalibrados podem não processar a matéria-prima de forma adequada, podendo gerar riscos à saúde de quem as consomem.

Seguindo o mesmo contexto, nas usinas B e D, as planilhas com registros de temperatura no quesito relacionado aos equipamentos não eram preenchidas adequadamente, onde, segundo Santos (2014), o preenchimento dos registros faz-se necessário, pois assim tem-se um controle, rastreabilidade e histórico maior do produto que foi produzido, bem como todos os detalhes do seu processo de produção.

Para o quesito dos manipuladores (Gráfico 3), todos colaboradores possuíam uniformes de trabalho de cor clara e adequados às atividades na área de produção, estando limpos e em bom estado de conservação. Não havia também trabalhadores com ferimentos expostos ou afecções cutâneas passíveis de contaminação do alimento, além de que, os mesmos não fumavam, tossiam ou espirravam sobre os alimentos. Entretanto, apesar das conformidades observadas acima, foram observados padrões de não conformidades graves como ausência de máscara ao recepcionar a matéria prima, manipuladores com barbas compridas, além da não realização da lavagem das mãos e das botas durante as atividades no interior da indústria nos estabelecimentos $\mathrm{B}, \mathrm{C}$ e $\mathrm{D}$, atos que certamente poderiam contaminar o leite a ser beneficiado.


O item 4.6.6 da RDC no 216 da Anvisa (2004) proíbe o uso de barba por parte dos trabalhadores de estabelecimentos produtores e industrializadores de alimentos. Baptista \& Saraiva (2003), também relataram que não é aconselhável o uso de barba em estabelecimentos industrializadores de alimentos, pelo fato de poder favorecer a contaminação física e/ou biológica do alimento a ser processado. Esses autores, por sua vez, também afirmam que o uso de máscara nasobucal é essencial para diminuir a probabilidade de contaminação do alimento. Moreira et al. (2016), em trabalho realizado para averiguar a prevalência de Staphylococcus aureus em manipuladores de alimentos, relataram que de 25 manipuladores de produtos alimentícios, $48 \%$ (12) eram portadores desse microrganismo na mucosa nasal, e isso comprova a real necessidade do uso de máscaras na elaboração de produtos alimentícios. A presença de Staphylococcus aureus em alimentos segundo Xavier et al. (2007) representa um risco eminente do ponto de vista de saúde pública, pelo fato desse microrganismo liberar toxinas que podem causar intoxicação alimentar em poucas horas após a ingestão do alimento contaminado.

Nenhum dos estabelecimentos possuía os registros relacionados aos programas de capacitação e de higiene pessoal para a manipulação dos alimentos. Onde, Segundo a Emater (2009) e Matsubara et al. (2011), os responsáveis pelo estabelecimento devem tomar providências para que todos os trabalhadores 
envolvidos diretamente com o processo de recepção da matéria-prima e preparo do alimento recebam treinamentos e instruções de como recepcionar e produzir um produto final seguro. Ainda no quesito dos manipuladores, Santos \& Hoffmann (2010), também encontraram padrões de não conformidades bastante similares ao presente estudo, observando não conformidades referentes à ausência de capacitação dos manipuladores de alimentos, além de baixas conformidades no cumprimento de alguns hábitos higiênicos, afirmando que essas não conformidades são preocupantes, pelo fato dos manipuladores estarem diretamente ligados ao alimento.

Com relação ao quesito de produção e transporte do alimento (Gráfico 4), todos os estabelecimentos possuíam controle da circulação e acesso pessoal, mantendo-se ordenados e sem cruzamentos. A recepção da matéria-prima ocorria em local protegido e isolado da área de processamento, sendo todas inspecionadas na recepção, as embalagens eram acondicionadas em locais adequados em todas as usinas, com exceção do estabelecimento B, que apesar de mantê-las guardadas em local adequado, era comum manter embalagens que seriam utilizadas no dia, no piso da sala de processamento da indústria, o que poderia contaminar o leite já pasteurizado na hora do envase. Silva et al. (2010) relataram que as embalagens devem ser acondicionadas em locais com boas condições higiênico-sanitárias, logo, o piso não é o local mais adequado.

Além da não conformidade mencionada no parágrafo anterior, o estabelecimento $\mathrm{B}$ não preenchia adequadamente as planilhas de controle da recepção da matéria-prima, além disso, também foi verificada não conformidade quanto ao armazenamento do produto final, pois alguns produtos estavam sendo armazenados na câmara fria em contato direto com o piso. Machado et al. (2015), relataram que o produto final deve ser acondicionado em prateleiras, não devendo estar em contato direto com o chão. Por sua vez, Silva et al. (2010) relataram que ao manter o produto final acondicionado em prateleiras ou pallets, evita-se danos, alterações ou contaminações na embalagem, melhorando assim a qualidade do alimento produzido para o consumidor.

No estabelecimento B, na câmara fria, também foi constatada a presença de queijos em estado de putrefação (Figura 4A e 4B), o que pode indicar uma possível falha nos programas de recolhimento de alimentos. No estabelecimento D, foi observada a presença de um frasco de fosfatase alcalina (Figura $\underline{4 C}$ ), ou seja, material inconveniente para o local. Silva et al. (2010), também observaram produtos não alimentícios na câmara fria de alguns laticínios em seu estudo.



Figura 4. Não conformidades verificadas nos estabelecimentos produtores de leite caprino da região do carirì paraibano. A e B: Queijos estragados na câmara fria; C. Fosfatase alcalina na câmara fria.

No quesito relacionado à documentação, como demonstrado no gráfico 5 , destacam-se as usinas $\mathrm{B}$ e $\mathrm{D}$, que apresentaram valores de não conformidades muito próximo aos de conformidades. Quintão et al. (2013) em seu estudo observaram $51,25 \%$ de não conformidades para esse quesito, resultado muito próximo ao apresentado nesses dois estabelecimentos do presente estudo.

Nenhuma usina apresentou $100 \%$ de conformidades para esse quesito, todas apresentaram falhas no cumprimento dos Programas Operacionais Padronizados (POPs). Todos os estabelecimentos também apresentaram não conformidade referente à documentação de manutenção preventiva e da calibração dos equipamentos, também não foram observados nos estabelecimentos $\mathrm{B}$ e $\mathrm{C}$ documentos e registros 
relacionados à higiene e saúde dos manipuladores, e na usina $\mathrm{B}$ também não eram cumpridos os programas de recolhimento de alimentos, o que poderia causar contaminação cruzada.

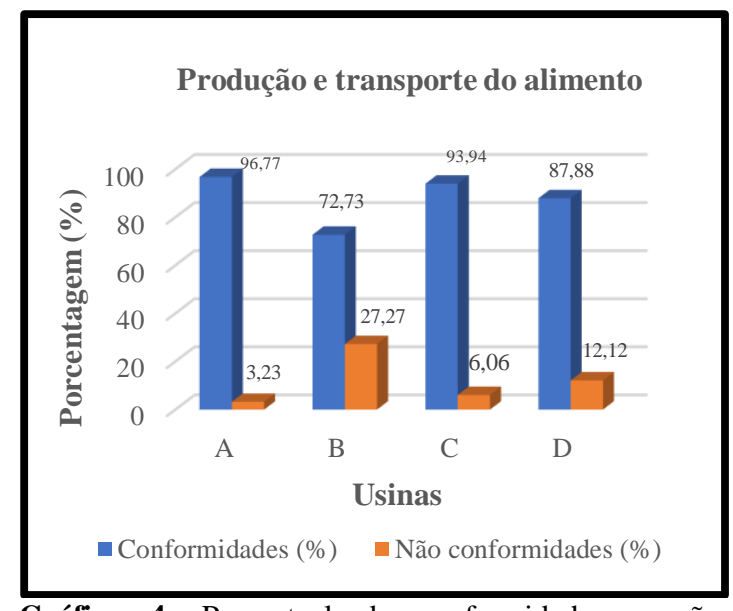

Gráfico 4. Percentual de conformidades e não conformidades para o quesito de produção e transporte do alimento.

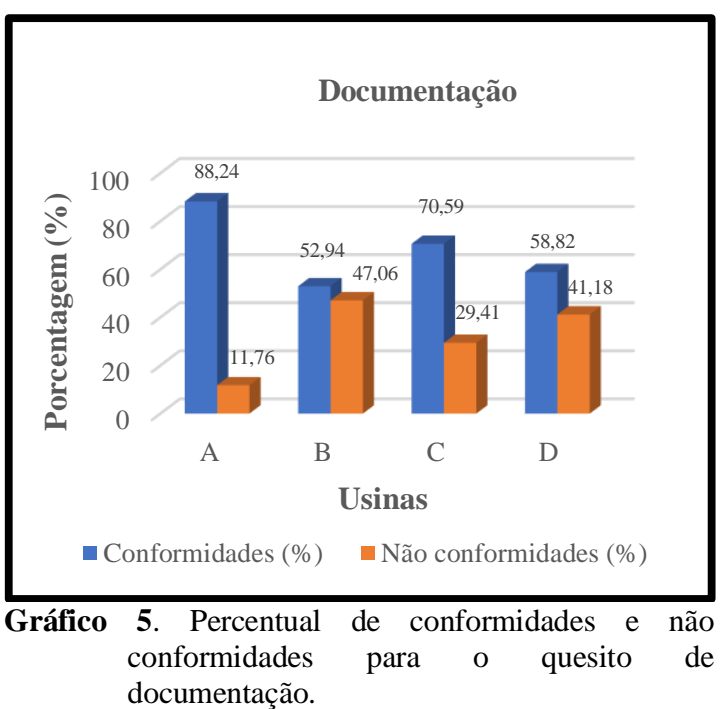

documentação.

Segundo Oliveira et al. (2018), as documentações, juntamente com os registros, compreendem um dos quesitos mais importantes para uma boa implementação das BPFs, pois fornecem as descrições de procedimentos da matéria-prima, dos equipamentos e de práticas higiênicas na indústria, o que garante um alimento seguro para o consumidor. Silva \& Correia (2011) também demonstraram a importância da implementação dos POPs para um bom controle das condições de produção e da segurança alimentar em indústrias alimentícias.

Conforme podemos observar, o gráfico 6 expressa a média que todos estabelecimentos da presente pesquisa apresentou em relação aos quesitos da lista de verificação. Pode-se observar que os quesitos que apresentaram os maiores percentuais de conformidades foram os referentes aos equipamentos, móveis e utensílios, com 88,1\% de conformidades; produção e transporte dos alimentos com 87,8\% de conformidades; manipuladores com $80,4 \%$ de conformidade. Observa-se também que os maiores problemas apresentados nos estabelecimentos (menor percentual de conformidades) foram referentes as edificações e instalações, com 71,5\% de conformidades e no quesito de documentação, com apenas $67,64 \%$ de conformidades.

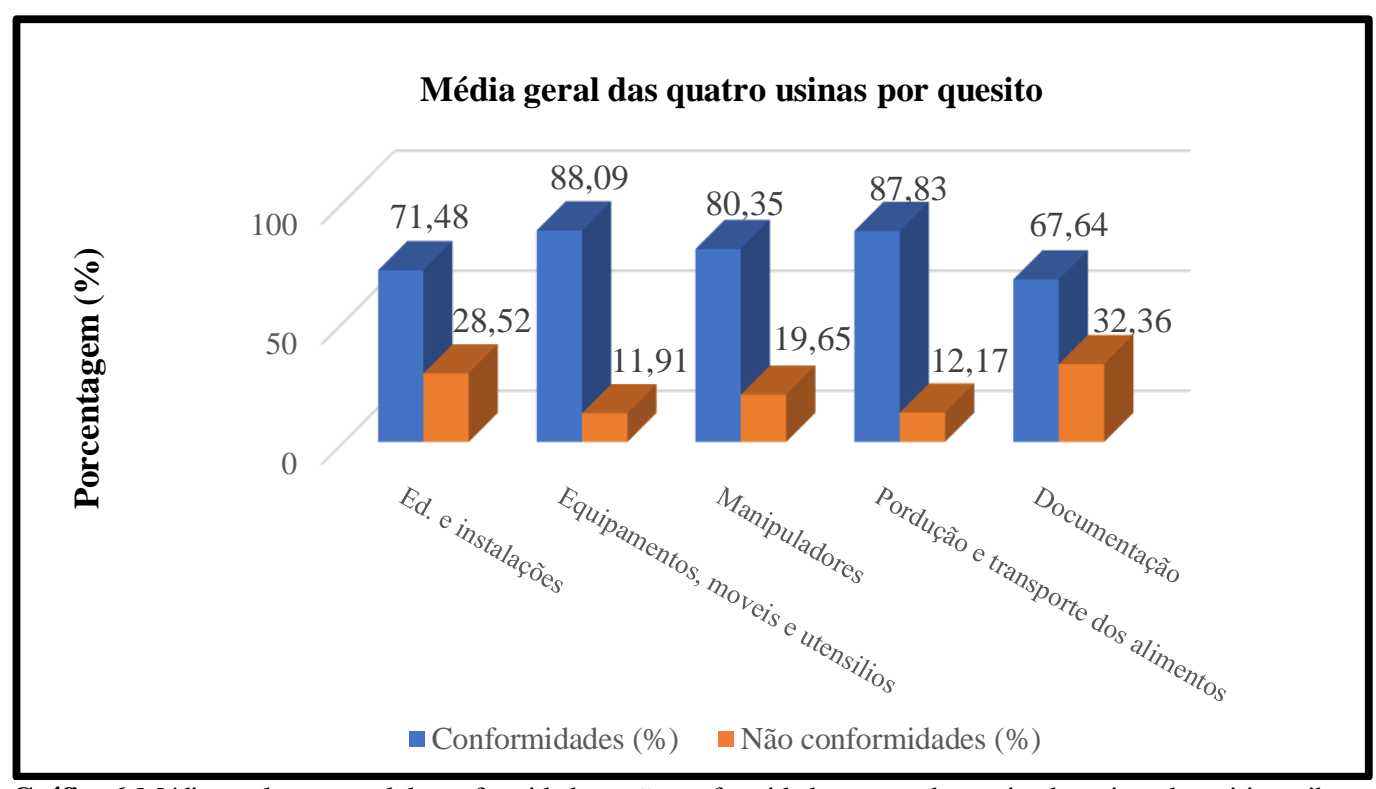

Gráfico 6. Média geral percentual de conformidades e não conformidades para cada quesito das usinas do cariri paraibano.

Sugere-se que as usinas de beneficiamento pesquisadas melhorem a qualidade de suas edificações e instalações, realizem mais treinamentos em seus manipuladores e aumentem os níveis percentuais 
relacionados às documentações, visto que foram os quesitos que apresentaram maiores percentuais gerais de não conformidade.

\section{Conclusão}

Assim sendo, com o presente estudo, foi possível concluir que dos quatro estabelecimentos avaliados, dois obtiveram baixo nível de conformidade de acordo com a lista de verificação aplicada, apresentando inconformidades graves. Isso demonstra que apesar dos estabelecimentos estarem registrados em um serviço de inspeção, ainda sim podem apresentar falhas graves que poderão ocasionar em inseguranças e comprometer a qualidade dos alimentos produzidos e consequentemente oferecer riscos à saúde de quem os consomem. Os órgãos competentes, por sua vez, devem realizar mais auditorias com o intuito de fazer uma fiscalização e punição mais efetiva aos estabelecimentos que descumpram as normas de BPFs, visto que esse programa compreende procedimentos essenciais que garantem uma melhor qualidade, segurança e consequentemente maior aceitação dos produtos por parte dos consumidores.

\section{Referências bibliográficas}

Agência Nacional de Vigilância Sanitária (ANVISA). (2002). Regulamento Técnico de Procedimentos Operacionais Padronizados Aplicados aos Estabelecimentos Produtores/ Industrializadores de Alimentos. Resolução RDC n ${ }^{\circ} 275$, de 21 de outubro de 2002.

Agência Nacional de Vigilância Sanitária (ANVISA). (2004). Regulamento Técnico de Boas Práticas para Serviços de Alimentação. Resolução RDC n 216, de 15 de setembro de 2004.

Bandeira, D. A., Castro, R. S., Azevedo, E. O., Melo, L. S. S., \& Melo, C. B. (2007). Características de produção da caprinocultura leiteira na região do Cariri na Paraíba. Ciência Veterinária Nos Trópicos, 10(1), 29-35.

Baptista, P. \& Saraiva, J. (2003). Higiene pessoal na indústria alimentar. Guimarães: FORVISÃO Consultoria em Formação Integrada LDA.

Cardozo, G. M. B. Q. (2007). Avaliação de Musca domestica como vetor mecanico de microrganismos patogenicos em queijo minas frescal. [sn].

Empresa de Assistência Técnica e Extensão Rural (EMATER). (2009). Guia Técnico para a Implantação de Boas Práticas de Fabricação em Unidades de Produção do Queijo Minas Artesanal. Disponível em: https://www.emater.mg.gov.br/doc/intranet/upload/QUEIJO_SITE/cartilha_queijo\%202.pdf. Acesso em: 15 de nov. de 2020.

Ferreira, C. E. M., Bezerra, L. G., \& Neto, G. V. (2004). Guia para implantação de boas práticas de fabricação (BPF) e do Sistema APPCC. Rio de Janeiro.

Figueiredo, E. L., Melo, J. K. L., \& Neves, N. C. O. (2016). Diagnóstico higiênico-sanitário e da qualidade microbiológica de produtos lácteos em um Laticínio localizado em Tucuruí-Pará. Revista Do Instituto de Laticínios Cândido Tostes, 71(2), 53-64. https://doi.org/10.14295/22386416.v71i2.466.

Germano, P. M. L., \& Germano, P. M. L. (2008). Higiene e vigilância sanitária de alimentos. Manole.

Góes, B. C., \& Silva, C. E. (2011). Análise de layout do sistema produtivo de beneficiadora de leite: o caso dos empreendimentos do município de Antas, Bahia. Revista Gestão Industrial, 7(3), 41-49. https://doi.org/10.3895/S1808-04482011000300003.

Instituto Brasileiro de Geografia e Estatística (IBGE). (2017). Censo Agropecuário, 2017. Disponível em:<https://www.ibge.gov.br/estatisticas/economicas/agricultura-e-pecuaria/21814-2017-censoagropecuario.html?=\&t=resultados $>$. Acesso em: 15 de nov. de 2020.

Machado, R., Dutra, A., \& Pinto, M. (2015). Boas Práticas de Fabricação (BPF). Embrapa Agroindústria de Alimentos. Rio de Janeiro.

Magalhães, M. A., Dias, G., Milagres, M. P., Ottomar, M., \& Soares, C. F. (2006). Implantação das boas práticas de fabricação em uma indústria de laticínios da zona da mata mineira. Congresso Brasileiro de Qualidade.

Matsubara, M. T., Beloti, V., Tamanini, R., Fagnani, R., Silva, L. C. C., Monteiro, A. A., Battaglini, A. P. P., Ortolani, M. B. T., \& Barros, M. A. F. (2011). Boas práticas de ordenha para redução da 
contaminação microbiológica do leite no agreste Pernambucano. Semina: Ciências Agrárias, 32(1), 277-285. https://doi.org/10.5433/1679-0359.2011v32n1p277.

Moreira, G. S., Peder, L. D., \& Silva, C. M. (2016). Prevalência de Staphylococcus aureus nos vestíbulos nasais e mãos de manipuladores de alimentos em um hospital do oeste do Paraná, Brasil. Revista Uniná Review, 28(1), 51-55.

Novo, A. L. M., \& Schiffler, E. (2006). Princípios básicos para a produção econômica de leite. In Embrapa Pecuária Sudeste.

Okura, M. H., \& Moacir, J. (2010). Avaliação das condições higiênico-sanitárias de queijos minas frescal produzidos com leite cru, leite pasteurizado e dequeijo temperado em alguns municípios da região do triângulo mineiro. Revista Do Instituto de Laticínios Cândido Tostes, 65(375), 33-42.

Oliveira, S. C. P. L., Silva, A. C., \& Carvalho, M. das G. X. (2018). Diagnóstico das condições higienicossanitárias do processo de fabricação de queijo de coalho no Sertão Paraibano. Higiene Alimentar, 284/285, 66-71.

Poerner, N., Rodrigues, E., Palhano, A. L., \& Fiorentini, Â. M. (2009). Avaliação das condições higiênico-sanitárias em serviços de alimentação. Revista Do Instituto Adolfo Lutz, 68(3), 399-405.

Quintão, C. S. C., Pereira, D. C. S., Silvério, A. de F., Reis, M. R. R., Martins, A. D. O., \& Martins, M. L. (2013). Avaliação das boas práticas de fabricação em laticínio do município de Rio Pomba, MG. Higiene Alimentar, 226/227, 69-72.

Rubin, F. H., Cerbaro, K., Naumann, V., Brunelli, A. V, \& Coser, J. (2012). Avaliação microbiológica das mãos, utensílios, e superfície dos manipuladores de alimentos em entidades do banco de alimentos de Cruz Alta. XVII Seminário Interinstitucional de Ensino, Pesquisa e Extensão, XV Mostra de Iniciação Científica e X Mostra de Extensão. Unicruz., 17.

Santos, L. V. (2014). Avaliação das boas práticas de fabricação em agroindústrias do Distrito Federal (DF). In Nutrição: Vol. Monografia. Universidade de Brasília.

Santos, V. A. Q., \& Hoffmann, F. L. (2010). Avaliação das boas práticas de fabricação em linha de processamento de queijos Minas frescal e ricota. Revista Do Instituto Adolfo Lutz, 67(387), 222-228.

Secretaria de Vigilância Sanitária do Ministério da Saúde (SVS/MS). (1997). Regulamento Técnico Sobre as Condições Higiênico-Sanitárias e de Boas Práticas de Fabricação para Estabelecimentos Produtores/Industrializadores de Alimentos. Portaria n 326, de 30 de julho de 1997. Disponível em: https://bvsms.saude.gov.br/bvs/saudelegis/svs1/1997/prt0326_30_07_1997.html Acesso em: 13 de nov. de 2020.

Silva, F. T., Farias, A. X., Nascimento Neto, F. dos, \& Machado, R. L. P. (2010). Boas práticas de fabricação em laticínios: principais não conformidades. Higiene Alimentar, 24(180/181), 52-58.

Silva, L. A., \& Correia, A. F. K. (2011). Manual de boas práticas de fabricação para indústria fracionadora de alimentos. Revista de Ciência \& Tecnologia, 16(32), 39-57.

Siqueira, L. P., Shinohara, N. K. S., Lima, R. M. T., Paiva, J. do E., Lima Filho, J. L., \& Carvalho, I. T. (2010). Avaliação microbiológica da água de consumo empregada em unidades de alimentação. Ciência \& Saúde Coletiva, 15, 63-66. https://doi.org/10.1590/S1413-81232010000100011.

Xavier, C. A. C., Oporto, C. F. O., Silva, M. P., Silveira, I. A., \& Abrantes, M. R. (2007). Prevalência de Staphylococcus aureus em manipuladores de alimentos das creches municipais da cidade do Natal/RN. Revista Brasileira de Análises Clínicas, 39(3), 165-168.

Histórico do artigo:

Recebido: 27 abril de 2021

Aprovado: 23 de maio de 2021
Licenciamento: Este artigo é publicado na modalidade Acesso Aberto sob a licença Creative Commons Atribuição 4.0 (CC-BY 4.0), a qual permite uso irrestrito, distribuição, reprodução em qualquer meio, desde que o autor e a fonte sejam devidamente creditados. 